\title{
Educação física, saúde e formação profissional
}

\section{| ${ }^{1}$ Rogério Cruz de Oliveira |}

\author{
1 Departamento de Ciências do Movimento Humano, Universidade Federal de São Paulo. Santos-SP, Brasil (rogerio.unifesp@gmail.com). \\ ORCID: 0000-0002-8615-0397. \\ Recebido em: 29/03/2018 \\ Aprovado em: 29/03/2018 \\ Revisado em: 20/08/2018
}

DOI: http://dx.doi.org/10.1590/S0103-73312018280302

O tradicional argumento da Educaçáo Física (EF) no campo da saúde gravita em torno das contribuiçóes desta à promoção da saúde, entendendo, principalmente, que um aumento do nível de atividade física da população contribui positivamente à saúde e qualidade de vida das pessoas, fato este com o qual também fazemos coro. Entretanto, a discussão acumulada nas últimas duas décadas fez com que esse enfoque se ampliasse e colocasse a EF na esteira da produção de cuidado em saúde para além das dimensôes orgânico-funcionais, principalmente com a incorporação da saúde coletiva na produção acadêmica da área, que, para Bagrichesvky (2007), foi praticamente inexistente na década de 1980.

Consequentemente, pouca atenção tem se dado à relaçấo da formação profissional em EF com a saúde. Para ilustrar o fato, recorremos a duas publicações da Revista Physis, em 2009: Anjos e Duarte (2009) e Brugnerotto e Simões (2009).

No estudo de Anjos e Duarte (2009), os resultados apontam para um não direcionamento dos cursos de graduação em Educação Física para a área da saúde; as disciplinas que transversam esse conhecimento são de natureza prescritiva; e não há estágio nos serviços de saúde. As pesquisadoras investigaram três instituiçôes públicas de ensino superior do Estado de São Paulo, que, de acordo com os critérios apresentados, possuem destaque na formação profissional em EF. 
Em Brugnerotto e Simões (2009), os resultados evidenciaram a predominância de uma concepção restrita de saúde nos cursos de EF, fortemente relacionada com a perspectiva biológica. Para os autores, tal resultado remete à preocupação de que a justificativa de intervenção em EF limite-se apenas à relação causal entre atividade física e saúde.

Saindo do escopo da Physis, o estudo de Pasquim (2010) demonstrou que a Saúde Coletiva é uma disciplina marginalizada, isolada e com pequena carga horária nos currículos de graduação em EF. Para o autor, isso não causa impacto sobre a formação profissional em EF.

Como atenuante, um fato que merece destaque é a regulamentação do profissional de EF como profissional de saúde pela Resolução 218/97 (BRASIL, 1997). Ou seja, somente há 19 anos há o entendimento legal da relação entre a EF e o campo da saúde, mesmo que este venha se desenvolvendo desde o século XIX, na gênese da EF. Tal fato permite a compreensão de que são recentes os enlaces da EF com o Sistema Único de Saúde (SUS), bem como de todos os seus desdobramentos, inclusive a formação de profissionais.

De acordo com Fraga et al., (2015), o SUS não é sequer mencionado nas Diretrizes Curriculares Nacionais para a formação do profissional de Educação Física (BRASIL,2004). Para os autores, esse "silenciamento" do SUS nas diretrizes de formação da área contrasta, por exemplo, com a inserção da EF em açôes programáticas da Estratégia Saúde da Família (ESF) e do Núcleo de Apoio à Saúde da Família (Nasf). Isso “[...] indica, tanto para o campo da saúde quanto para a área da Educação Física, a potencialidade deste profissional na articulação de práticas de cuidado de caráter multiprofissional, inspiradas no princípio da integralidade da atenção" (FRAGA et al., 2015, p. 379).

Frente ao exposto, parece urgente que a EF repense a saúde em seus currículos de formação na direção do SUS, que tem valorizado as açóes da área por meio do binômio práticas corporais/atividade física. Por mais críticas que se faça a esse termo, principalmente por unir duas compreensóes distintas, respectivamente, cultural e biológica, é ele que tem dado legitimidade à existência do profissional de EF na saúde.

Nesse sentido, é oportuno frisar a existência de duas iniciativas curriculares no Brasil que contemplam o pensamento acima: o curso de EF da Universidade Federal de São Paulo - Campus Baixada Santista, e o curso de EF e Saúde da Universidade de São Paulo (Escola de Artes, Ciências e Humanidades). Para Fonseca et al. (2012), 
esses dois cursos consistem em experiências pioneiras na formação em EF e saúde. Além desses projetos de formação, existem atualmente outros cinco em andamento no país: Educação Física, na Universidade Federal do Rio Grande do Sul; Educação Física - ênfase em Educação Física e Saúde, na Universidade Federal do Maranhão; Educação Física - ênfase em promoção da saúde e lazer, na Universidade Federal do Amazonas; Educação Física - ênfase em Educação Física e Saúde, na Universidade de São Paulo (Escola de Educação Física e Esporte de Ribeirão Preto); e Educação Física - ênfase em Educação Física e Saúde, na Universidade Ibirapuera. Essas sete experiências curriculares, localizadas em duas regiōes do país (Norte e Sudeste), compóem o universo de 1.329 cursos de EF presenciais no Brasil.

Nessa esteira, é possível concordar com Andrade e Oliveira (2016), para os quais a formação profissional em EF e saúde se encontra deficitária diante das demandas do Sistema Único de Saúde (SUS). Dessa forma, compreendemos que a EF ainda tem um longo e promissor caminho a percorrer no horizonte da Saúde Coletiva como tema imprescindível à formação profissional. Nesse sentido, acredita-se que o apreender os desdobramentos das experiências curriculares em EF e Saúde em andamento no Brasil seja um primeiro passo, que, para além de coerente, parece ser prudente.

\section{Referências}

ANDRADE, D. R.; OLIVEIRA, R. C. Formação profissional em Educação Física para o setor da saúde e as Diretrizes Curriculares Nacionais. Pensar a Prática. Goiânia, v. 16, n. 4, p. $722-$ 733, 2016.

ANJOS, T. C.; DUARTE, A. C.G.O. A educação física e a estratégia de saúde da família: formação e atuação profissional. Physis - Revista de Saúde Coletiva. Rio de Janeiro, v. 19, n. 4, p. $1127-1143,2009$.

BAGRICHEVSKY, M. A formação profissional em Educação Física enseja perspectivas (críticas) para a atuação na saúde coletiva? In: FRAGA, A.; WACHS, F. (Orgs.). Educação Física e saúde coletiva: políticas de formação e perspectivas de intervenção. Porto Alegre: UFRGS, 2007 p. 33-46.

BRASIL. Resolução n. 7, de 31 de março de 2004. Institui as Diretrizes Curriculares Nacionais para os cursos de graduação em Educação Física, em nível superior de graduação plena. Brasília, DF: Diário Oficial da República Federativa do Brasil, 5 abr. 2004.

. Resolução n. 218, de 6 de março de 1997. Reconhecimento de profissionais de saúde de nível superior. Brasília, DF: Diário Oficial da República Federativa do Brasil, 5 maio 1997. 
BRUGNEROTTO, F.; SIMÓES, R. Caracterização dos currículos de formação profissional em educação física: um enfoque sobre saúde. Physis - Revista de Saúde Coletiva. Rio de Janeiro, v. 19, n. 1, p. 149-172, 2009.

FONSECA, S. A. et al. Notas preliminares sobre a Associação Brasileira de Ensino da Educação Física para a saúde - Abenefs. Caderno Fnepas, Brasília, v. 2, s/n, p. 38-48, 2012.

FRAGA, A. B.; GOMES, I.; CARVALHO, Y. M. Políticas de formação em Educação Física e Saúde Coletiva. Trabalho, Educação e Saúde. Rio de Janeiro, v. 10, n. 3, p. 367-386, 2012.

PASQUIM, H. M. A Saúde Coletiva nos Cursos de Graduação em Educação Física. Saúde e Sociedade. São Paulo, v. 19, n. 1, p. 193-200, 2010. 